\title{
Exploring the association between pain intensity and facial display in term newborns
}

\author{
Martin Schiavenato PhD RN ${ }^{1,2}$, Meggan Butler-O'Hara RN MSN NNP PNP ${ }^{3}$, Paul Scovanner MS ${ }^{4}$
}

\begin{abstract}
M Schiavenato, M Butler-O'Hara, P Scovanner. Exploring the association between pain intensity and facial display in term newborns. Pain Res Manage 2011;16(1):10-12.
\end{abstract}

BACKGROUND: Facial expression is widely used to judge pain in neonates. However, little is known about the relationship between intensity of the painful stimulus and the nature of the expression in term neonates. OBJECTIVES: To describe differences in the movement of key facial areas between two groups of term neonates experiencing painful stimuli of different intensities.

METHODS: Video recordings from two previous studies were used to select study subjects. Four term neonates undergoing circumcision without analgesia were compared with four similar male term neonates undergoing a routine heel stick. Facial movements were measured with a computer using a previously developed 'point-pair' system that focuses on movement in areas implicated in neonatal pain expression. Measurements were expressed in pixels, standardized to percentage of individual infant face width.

RESULTS: Point pairs measuring eyebrow and eye movement were similar, as was the sum of change across the face (41.15 in the circumcision group versus 40.33 in the heel stick group). Point pair 4 (horizontal change of the mouth) was higher for the heel stick group at 9.09 versus 3.93 for the circumcision group, while point pair 5 (vertical change of the mouth) was higher for the circumcision group (23.32) than for the heel stick group (15.53).

CONCLUSION: Little difference was noted in eye and eyebrow movement between pain intensities. The mouth opened wider (vertically) in neonates experiencing the higher pain stimulus. Qualitative differences in neonatal facial expression to pain intensity may exist, and the mouth may be an area in which to detect them. Further study of the generalizability of these findings is needed.

Key Words: Computer measurement; Facial expression; Neonatal pain; Pointpair method; Primal face of pain

\section{Explorer l'association entre l'intensité de la douleur et l'expression faciale chez les nouveau-nés à terme}

HISTORIQUE : L'expression faciale est largement utilisée pour évaluer la douleur chez le nouveau-né. Cependant, on ne sait pas grand-chose du lien entre l'intensité du stimulus douloureux et la nature de l'expression chez les nouveau-nés à terme.

OBJECTIFS : Décrire les différences dans le mouvement des principales régions faciales de deux groupes de nouveau-nés à terme qui connaissent des stimulus douloureux de différentes intensités.

MÉTHODOLOGIE : Les chercheurs ont utilisé les enregistrements vidéo de deux études antérieures pour sélectionner les sujets à l'étude. Ils ont comparé quatre nouveau-nés à terme qui étaient circoncis sans analgésie à quatre nouveau-nés à terme similaires de sexe masculin qui subissaient une piqûre du talon systématiquement. Ils ont mesuré les mouvements faciaux à l'ordinateur au moyen d'un système de « jumelage des paires » déjà mis au point dans les régions du visage utilisées pour exprimer la douleur néonatale. Les mesures étaient exprimées en pixels, normalisés d'après la largeur du visage de chaque enfant.

RÉSULTATS : Les points jumelés qui mesuraient les mouvements des sourcils et des yeux étaient similaires, tout comme la quantité de changement sur le visage $(41,15$ dans le groupe circoncis par rapport à 40,33 dans le groupe subissant la piqûre du talon). Le point jumelé 4 (changement horizontal de la bouche) était plus élevé, à 9,09, dans le groupe subissant la piqûre du talon que dans le groupe circoncis, à 3,93, tandis que le point jumelé 5 (changement vertical de la bouche) était plus élevé dans le groupe circoncis $(23,32)$ que dans le groupe subissant la piqûre du talon $(15,53)$.

CONCLUSIONS : On remarquait peu de différence dans le mouvement des yeux et des sourcils pour ce qui est de l'intensité des douleurs. La bouche s'ouvre plus largement (à la verticale) chez les nouveau-nés qui subissent le stimulus de douleur le plus élevé. Il existe peut-être des différences qualitatives d'expression faciale du nouveau-né par rapport à l'intensité de la douleur, et la région de la bouche est peut-être celle où on peut la déceler. D'autres études s'imposent sur la généralisabilité de ces observations.

tools such as the Premature Infant Pain Profile (7) and COMFORT (8) scales include varying levels of facial tension or grimacing as indicators of pain intensity. In the present study, we set out to empirically evaluate differences in facial grimacing between infants experiencing two levels of pain intensity using 'point-pair' computer-based methodology (9). An innovative feature of this approach is that the technique allows for fine ratio-level measurement of expressions; in contrast, current tools and methods provide a rougher estimation of intensity, generally at a nominal or categorical level. Evidence supporting the relationship between increased pain stimulus and increased facial tension, and perhaps a specific source or pattern associated with this tension, will provide support for current clinical tools and perhaps direct their improvement.
Facial actions are the most prominent, overt and consistent signs of (2). However, the association between pain intensity and neonatal facial display has not been explored experimentally. Ethical principles rightfully preclude the application of varying degrees of pain on human neonates. Previous studies (3-5) have assessed the association of facial expressions between invasive (painful) and noninvasive pro cedures (eg, rubbing the thigh with alcohol, or a diaper change) in newborns. These studies found increased facial action with invasive procedures. In adults, Kunz et al (6) found that an increase in intensity of a noxious stimulus led to a strong increase in facial expression. Clinically, the assumption is that higher pain intensity is associated with a more 'intense' facial display; for example, infant bedside pain
${ }^{1}$ University of Rochester School of Nursing; ${ }^{2}$ Department of Biomedical Engineering; ${ }^{3}$ Department of Pediatrics, Division of Neonatology,

University of Rochester, Rochester, New York; ${ }^{4}$ School of Electrical Engineering and Computer Science, University of Central Florida,

Orlando, Florida, USA

Correspondence: Dr Martin Schiavenato, University of Rochester Medical Center, PO Box SON, Rochester, New York 14642, USA.

Telephone 585-276-4037, fax 585-273-1270, e-mail martin_schiavenato@urmc.rochester.edu 
TABLE 1

Mean point-pair change results*

\begin{tabular}{|c|c|c|c|c|c|}
\hline Anatomical area & Functional area & Point pair & HEEL & CIRC & $\begin{array}{c}\text { Absolute change } \\
\text { (CIRC-HEEL) }\end{array}$ \\
\hline Between medial border of eyebrows & Brow bulge & 1 & -6.30 & -6.27 & 0.03 \\
\hline Mid eyebrow to mid lower eyelid (right) & Eye squeeze & 2 & -2.02 & -1.15 & 0.87 \\
\hline Mid eyebrow to mid lower eyelid (left) & Eye squeeze & 3 & -1.80 & -2.94 & 1.14 \\
\hline Between lip corners & Horizontal mouth movement & 4 & 9.09 & 3.93 & 5.16 \\
\hline Between medial upper and lower lip vermilion border & Vertical mouth movement & 5 & 15.53 & 23.32 & 7.79 \\
\hline Total change (absolute sum of point-pair change) & & & 40.33 & 41.15 & 0.82 \\
\hline
\end{tabular}

*Negative numbers imply drawing in or approximation of points, while positive numbers imply moving away or separation of points. CIRC Circumcision group; HEEL Routine heel stick group

\section{METHODS}

Video recordings from two previous studies were used to select possible candidates for inclusion. Group 1 (CIRC) consisted of four male neonates undergoing circumcision without analgesia. The four vintage videos used for this group were obtained from a previous study (10) exploring the utility of analgesia in circumcision. At that time, the standard of care in the United States was to not use analgesia during circumcision. These infants were part of the control group in that study that did not receive the then-novel approach of analgesia. Due to quality and clarity of images, only four videos from this study were deemed useful for the present study (eg, unobstructed view of the face during the procedure). Group 2 (HEEL) consisted of four male neonates undergoing a routine heel stick from a previous but more recent study (9). These four males were randomly selected from a group of 28 infants to match the CIRC group according to gestational age and ethnicity. Infants in both groups were undergoing 'standard' neonatal care and had no known illnesses or medical complications. All videos were converted digitally and two still pictures (baseline and reaction) were processed for each case in the manner described elsewhere (9). The baseline picture consisted of a neutral expression before the painful stimulus. The reaction picture in the CIRC group consisted of the maximum facial expression immediately after initiating the circumcision (clamping of the prepuce). The reaction picture in the HEEL group consisted of the maximum facial expression immediately after the heel stick. A measurement scheme evaluative of change between pairs of points (point pairs) on the face (9) was derived from the Neonatal Facial Coding System $(11,12)$, a commonly used research tool to evaluate facial action associated with pain in neonates and consisting of five previously implicated facial pain expression areas (between the eyebrows, between the bottom eyelid and eyebrow [for each eye], between the mouth corners, and between the top and bottom of the lips). This scheme allows for precise quantitative measurement of movement in key facial areas by comparing the difference in positions. Change $(c)$ was defined as the difference in point-pair measurement between pictures, calculated as $c=r-b$, where $b$ was the pointpair measurement in the baseline picture and $r$ was the point-pair measurement in the reaction picture. 'Total change' was the absolute sum of all five point-pair changes. Measurements were expressed in pixels and standardized to the percentage of each individual infant's face width, measured between their outer canthi. Measurements were performed in Matlab (MathWorks Inc, USA).

\section{RESULTS}

The infants had no history of developmental problems, neural impairments or delivery complications. They were all vaginally delivered, with an average gestational age of 39 weeks for each group. The CIRC group consisted of three Caucasians and one infant of African American/Caucasian descent. Ethnicity for the HEEL group consisted of three Caucasians and one African American. Point-pair measurement results for infants in each group are presented in Table 1. Upper facial action, ie, eyes and eyebrows (point pairs 1 to 3), was similar for both groups, as was the total change or absolute sum of all facial movements. Lower facial action, ie, mouth (point pairs 4 and 5), differed

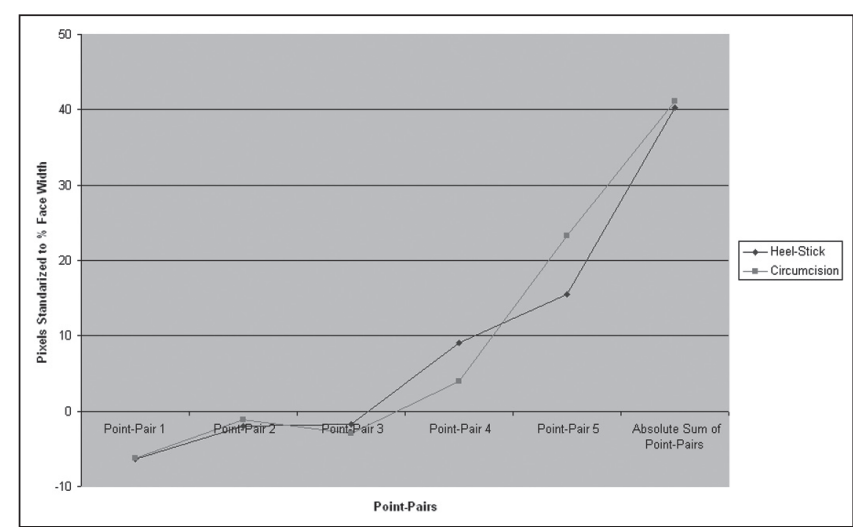

Figure 1) Graphic display of mean point-pair change

between the groups, with the CIRC group showing more vertical mouth movement (23.32 versus 15.53), while the HEEL group displayed more horizontal mouth movement (9.09 versus 3.93). A graphic display of mean point-pair change is provided in Figure 1.

\section{DISCUSSION}

An underlying assumption in the present study is that circumcision without analgesia is a more intense painful stimulus than a routine heel stick. In the routine heel stick procedure, an automatic lancet was used to make a superficial incision approximately $1 \mathrm{~mm}$ in depth and $2.5 \mathrm{~mm}$ in width. In contrast, the circumcision procedure at the moment that the facial expression was captured involved crushing the prepuce with a pair of hemostats inserted $5 \mathrm{~mm}$ to $10 \mathrm{~mm}$ into the prepuce. The prepuce is an area of complex somatosensory innervation evolved to function as erogenous tissue (13). As a result of significantly greater tissue insult in a highly sensitive area, a higher pain stimulus was assumed to occur in the circumcision group.

Pain expression in humans is concentrated in two areas - the mouth and the eyes (14). Facial expression of emotions in general can be classified into upper (eyes) and lower (mouth) facial areas. It is hypothesized that upper facial expressions are associated with primal types of displays and are modulated by the right brain hemisphere, while lower facial expressions or more socially modulated emotional displays are governed primarily by the left brain hemisphere (15). Although pain expression itself is not thought of as a 'pure emotion', it is thought to be primal, hardwired and innate, and most clearly presented as such in neonates who have little or no sociocultural inculcation (16). We found that both groups of neonates displayed similar eye movement, while infants experiencing the presumed higher painful stimulus (CIRC) displayed more vertical mouth movement. The vertical separation between the upper and lower lips explained the approximation of the corners of the mouth (horizontal mouth movement). It is possible that the differences in the mouth movement found here suggested an inability to regulate or sensor pain display in relation to stimulus intensity at birth. This might point both to a lack of mastery over emotional expression characteristic 


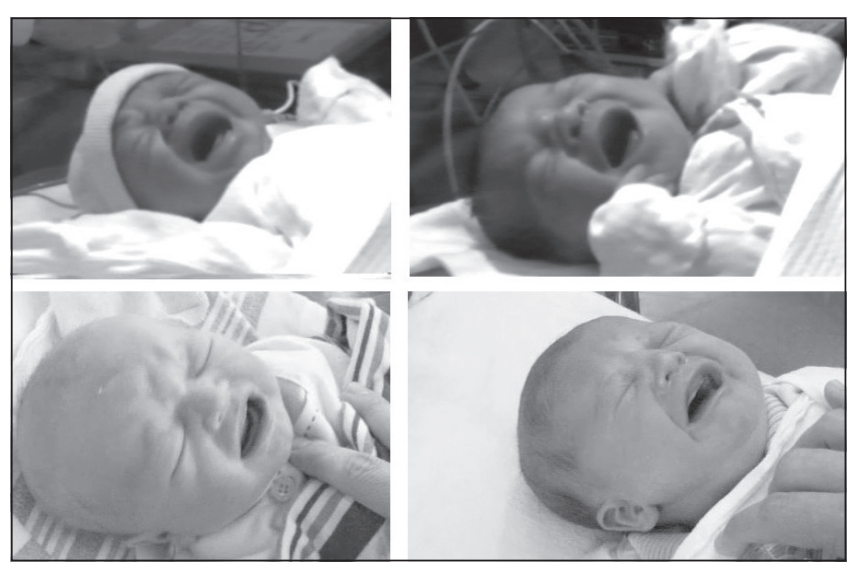

Figure 2) Neonatal facial pain response. Top row Circumcision without analgesia. Bottom row Routine heel stick

of the first year of life (17), as well as to the primacy and subtleness of the primal facial pain display in human neonates. That is, the primal face of pain evokes hardwired responses that may be sensitive to variation in stimuli intensity.

In the present analysis, the mouth (lower face) appeared better equipped to carry the message of pain intensity, showing greater range of movement and a more sensitive response than the upper face (eyes) to stimulus intensity. Curiously, adult observers of emotion also tend to focus on lower face displays more than upper face

\section{REFERENCES}

1. Slater R, Cantarella A, Franck L, Meek J, Fitzgerald M. How well do clinical pain assessment tools reflect pain in infants? PLoS Med 2008;5:e129.

2. Gibbins S, Stevens B, McGrath PJ, et al. Comparison of pain responses in infants of different gestational ages. Neonatology 2008;93:10-8.

3. Gibbins S, Stevens B, Beyene J, Chan PC, Bagg M, Asztalos E. Pain behaviours in extremely low gestational age infants. Early Hum Dev 2008;84:451-8.

4. Grunau RE, Johnston C, Craig AD. Neonatal facial and cry responses to invasive and non-invasive procedures. Pain 1990;42:295-305.

5. Holsti L, Grunau R, Oberlander TF, Osiovich H. Is it painful or not? Discriminant validity of the Behavioral Indicators of Infant Pain (BIIP) scale. Clin J Pain 2008;24:83.

6. Kunz M, Mylius V, Schepelmann K, Lautenbacher S. On the relationship between self-report and facial expression of pain. J Pain 2004:5:368-76.

7. Stevens B, Johnston C, Petryshen P, Taddio A. Premature Infant Pain Profile: Development and initial validation. Clin J Pain 1996;12:13-22.

8. Ambuel B, Hamlett KW, Marx CM, Blumer JL. Assessing distress in pediatric intensive care environments: The COMFORT scale. J Pediatr Psychol 1992;17:95-109.

9. Schiavenato M, Byers JF, Scovanner P, et al. Neonatal pain facial expression: Evaluating the primal face of pain. Pain $2008 ; 138: 460-71$ displays (18) (Figure 2). While these findings support the use of clinical tools assigning higher pain levels to those exhibiting higher intensities of facial expression, pain assessment in neonates may benefit from transcending such generalities as 'grimace' or 'facial tension' into a more specific evaluation of mouth (lower face) movement as an indicator of pain intensity.

The present study has several limitations. The small sample size precludes application beyond a descriptive nature. The present study is a retrospective analysis of two different groups, under somewhat similar conditions, standardized in a sense by the mechanics and requirements of the video measurement methodology. As mentioned above, ethical considerations preclude a similar comparison of painful procedures with no provision of appropriate analgesia in a prospective manner. In addition, this analysis is limited to one aspect of the pain expression - intensity of facial grimacing. Other factors related to the expression of pain, such as duration of the grimace, cry, etc, were not evaluated. Despite these limitations, the appreciation of the sensitivity of pain display in neonates is important and relevant in the development of improved techniques for its assessment. A focus on vertical mouth movement as a specific measure of pain intensity may advance the current development and refinement of standardized clinical and research pain tools in neonates. Furthermore, this knowledge may also help focus clinician bedside observation, as well as automated systems (19) to aid in clinical pain assessment. Future directions include the evaluation of other variables implicated in the facial expression of pain (eg, the development or progression of the expression, and the duration of the expression) and how these factors interact in the portrayal of pain intensity.

10. Butler-O'Hara M, LeMoine C, Guillet R. Analgesia for neonatal circumcision: A randomized controlled trial of EMLA cream versus dorsal penile nerve block. Pediatrics 1998;101:E5.

11. Grunau RV, Craig KD. Pain expression in neonates: Facial action and cry. Pain 1987;28:395-410.

12. Grunau RE, Oberlander T, Holsti L, Whitfield MF

Bedside application of the Neonatal Facial Coding System in pain assessment of premature neonates. Pain 1998;76:277-86.

13. Cold CJ, Taylor JR. The prepuce. BJU Int 1999;83(Suppl 1):34-44.

14. Prkachin K. Facial expressions as pain indicators. Nurs Times 1993;89:58.

15. Ross ED, Prodan CI, Monnot M. Human facial expressions are organized functionally across the upper-lower facial axis. Neuroscientist 2007;13:433-46.

16. Schiavenato M. Facial expression and pain assessment in the pediatric patient: The primal face of pain. J Spec Pediatr Nurs 2008;13:89-97.

17. Izard CE, Abe JA. Developmental changes in facial expressions of emotions in the strange situation during the second year of life. Emotion 2004:4:251-65.

18. Prodan CI, Orbelo DM, Ross ED. Processing of facial blends of emotion: Support for right hemisphere cognitive aging. Cortex 2007;43:196-206.

19. Brahnam S, Chuang C, Sexton R, Shih F. Machine assessment of neonatal facial expressions of acute pain. Decision Support Systems 2007;43:1242-54. 


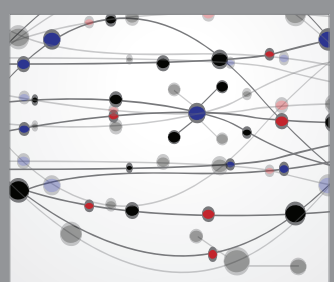

The Scientific World Journal
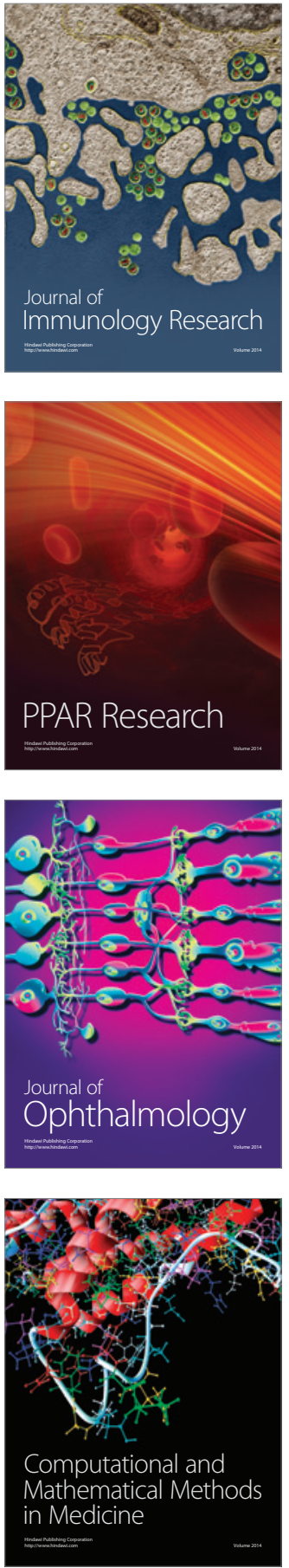

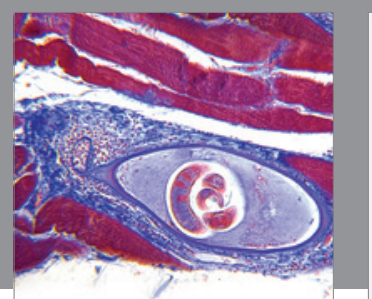

Gastroenterology Research and Practice

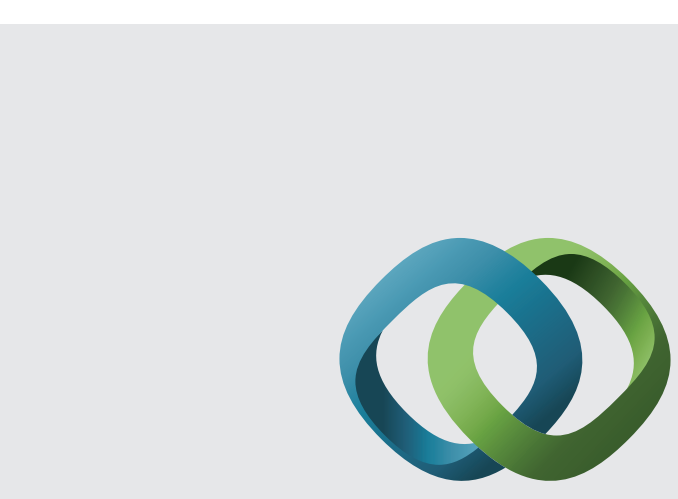

\section{Hindawi}

Submit your manuscripts at

http://www.hindawi.com
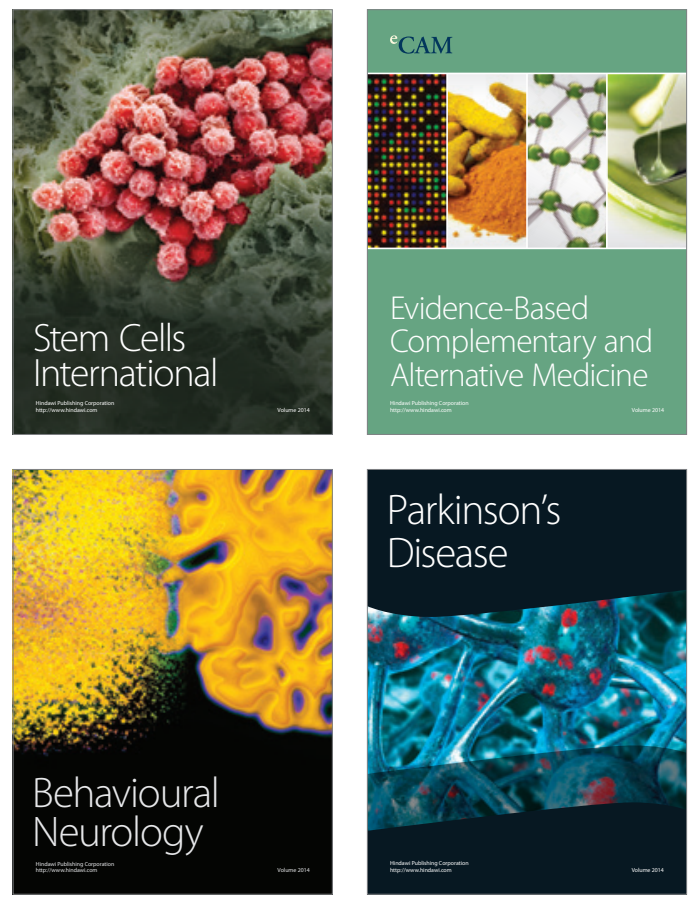
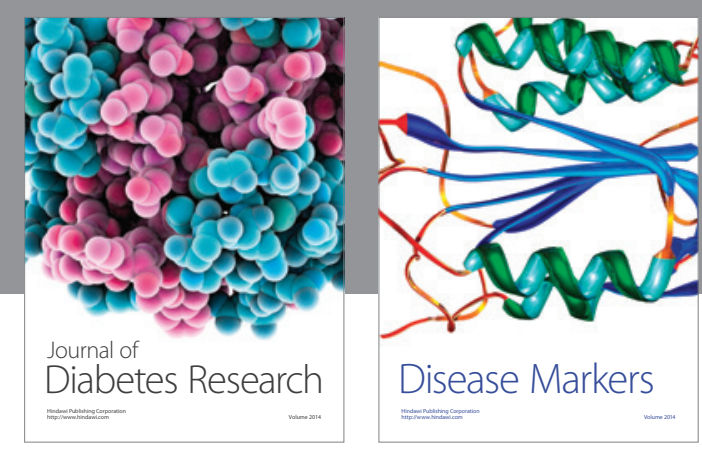

Disease Markers
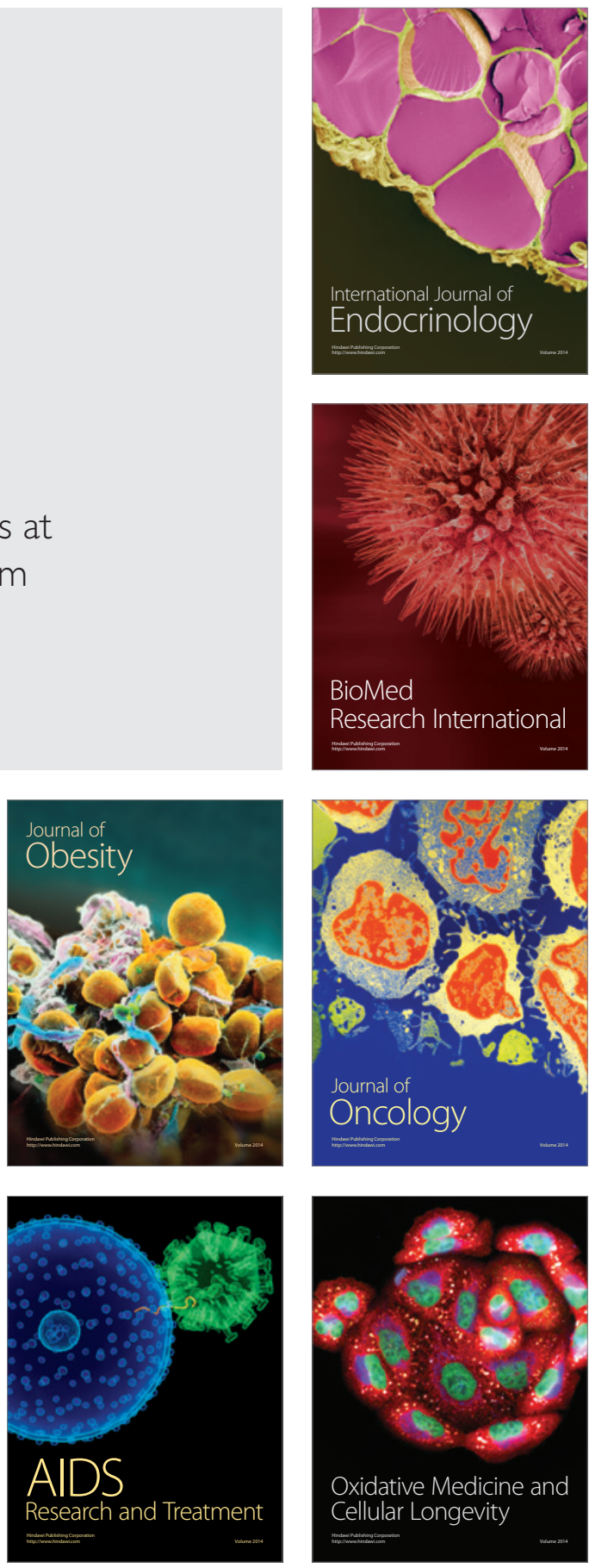